\title{
A Sensitive Period for the Neural Induction of Taste Buds
}

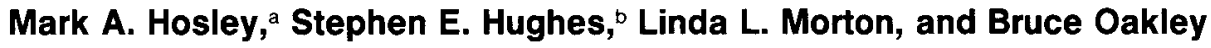 \\ Department of Biology, Neuroscience Laboratory Building, University of Michigan, Ann Arbor, Michigan 48109
}

\begin{abstract}
Taste buds mature postnatally in the vallate papilla of the rat and reach a mean number of 610 by day 90 . Although taste buds are neurotrophically dependent, the presence of widespread bilateral innervation permits more than $80 \%$ of the 610 vallate taste buds to survive after one IXth nerve is removed in adults. However, after a IXth nerve is removed at 0-3 d postpartum, about two-thirds of the vallate taste buds fail to develop. In the present investigation, the timing of the neural induction of taste buds was examined by unilaterally removing the IXth nerve at $\mathbf{1 2}$ different postnatal ages, from 0 to $75 \mathrm{~d}$. Unilateral denervation revealed the existence of a sensitive period that is maximal from 0 to 10 d, when unilateral or bilateral interruption of the IXth nerve profoundly impairs the formation of taste buds. The number of taste buds that form is nonlinearly dependent upon the number of axons; at low levels of innervation, a doubling of the number of myelinated axons quintuples the number of taste buds. Thus, taste axons interact synergistically. In studying regeneration, we found that axons of both neonatal and adult IXth nerves elongate approximately $1.8 \mathrm{~mm} / \mathrm{d}$. Taste buds were re-formed more rapidly and a higher proportion were bilaterally innervated when regenerating axons and the sites of former taste buds were numerous. The proportion of bilaterally innervated taste buds could be approximated from the likelihood of random overlap of axons from the right and left IXth nerves. The greater ease with which taste buds are re-formed than developed suggests that taste bud regeneration does not recapitulate taste bud development.
\end{abstract}

Hosley and Oakley (1987) have investigated the normal development and growth of the rat vallate papilla and the proliferation of its taste buds. In the rat, the vallate papilla occurs as a single midline structure near the posterior margin of the tongue. Mature vallate taste buds (those with a taste pore) appear only after birth and then continue to proliferate until they reach a maximum of 610 taste buds at day 90 postpartum. The maintenance and regeneration of taste buds in adult animals depends on the presence of an adequate nerve supply (von Vintschgau

\footnotetext{
Received July 21, 1986; revised Dec. 31, 1986; accepted Jan. 13, 1987.

We are grateful for the assistance of B. L. Bower and for the technical assistance provided by the laboratories of D. J. Chiego, C. F. Cox, and F. F. Ebner. This study is based in part on a dissertation submitted by M.A.H. in partial fulfillment of the requirements for the doctoral degree at the Rackham School of Graduate Studies at the University of Michigan. This research was supported in part by block grants from the University of Michigan Rackham School of Graduate Studies and by NIH Grant NS-07072.

Correspondence should be addressed to Bruce Oakley at the above address.

a Present address: Brown University Medical School, Providence, RI 02912.

b Present address: Central Institute for the Deaf and Department of Speech and Hearing, Washington University, St. Louis, MO 63110.

Copyright (C) 1987 Society for Neuroscience $0270-6474 / 87 / 072075-06 \$ 02.00 / 0$
}

and Hönigschmied, 1876; Guth, 1957; Oakley, 1970, 1974; Cheal and Oakley, 1977). In adult rats, unilateral avulsion of the IXth nerve results in a loss of only $5-19 \%$ of vallate taste buds because of bilateral overlap of the IXth nerves (Whiteside, 1927; Guth, 1963; Oakley, 1974; Hosley et al., 1987). The arrival of the nerve supply in the embryonic gustatory epithelium before the taste buds appear has raised the possibility that the taste buds require innervation in order to develop, i.e., that they are neurally induced (Hermann, 1884; Torrey, 1940; Farbman, 1965). In an experimental demonstration of neural induction, it was shown that early partial denervation can prevent almost twothirds of the vallate taste buds from developing (Hosley et al., 1987). Moreover, the inability of regenerating crushed axons to induce development of many of the missing taste buds raised the possibility of an early sensitive period for taste bud induction. In the present investigation we avulsed one IXth nerve at ages ranging from day 0 (birth) to day 75 and determined the number of taste buds present at later times. In other experiments we bilaterally interrupted the IXth nerve. The outcome of these procedures revealed the existence of a sensitive period that was maximal from 0 to $10 \mathrm{~d}$ postnatally.

\section{Materials and Methods}

Unilateral avulsion of the right glossopharyngeal nerve (IXth) was performed in a total of 150 Sprague-Dawley albino rats (Rattus norvegicus) at days $0,3,5,6,8,10,15,20,30,45,60$, and 75 postpartum. The abbreviations AVO/NORM through AV75/NORM indicate that the left IXth nerve was normal (undisturbed), whereas the right IXth nerve was avulsed from the tongue at the indicated postpartum age. Thus, in order to characterize the sensitive period for taste bud induction, the proliferation of taste buds in normal animals was compared with the number of taste buds arising after unilateral IXth nerve avulsion at different ages.

In addition, bilateral interruption of the IXth nerve was carried out in a total of 348 animals in 9 groups. The IXth nerve was crushed with 10-25 pinches with No. 5 watchmaker's forceps applied just proximal to the pharyngeal branch. Procedures for the 9 groups of animals were as follows:

(1) AV75/CR75: avulsion of the right IXth nerve and crush of the left IXth nerve at day $75 ; n=59$.

(2) AV75/CR75 + 82: the same surgery as above, combined with a second crush of the left IXth nerve 1 week later at day $82 ; n=39$.

(3) CR 3/AV75: crush of the right nerve at day 3 and avulsion of the left nerve at day $75 ; n=8$.

(4) AV3/CR3: avulsion of the right and crush of the left IXth nerve, both at day $3 ; n=59$.

(5) AV3/CR3 + 10: the same surgery as in (4), combined with a second crush of the left IXth nerve 1 week later at day $10 ; n=38$.

(6) AV3/CR 10: avulsion of the right IXth nerve at day 3 and crush of the left IXth nerve at day $10 ; n=63$.

(7) AV3/CR10 + 17: the same surgery as in (6), combined with a second crush of the left IXth nerve 1 week later at day $17 ; n=44$.

(8) CR3/CR 3: bilateral crush of the IXth nerve at day $3 ; n=32$.

(9) CR3 + AV75/CR3: the same surgery as in (8), combined with avulsion of the crushed right IXth nerve at day $75 ; n=6$.

Nerve surgery was carried out with ether anesthesia for animals less 


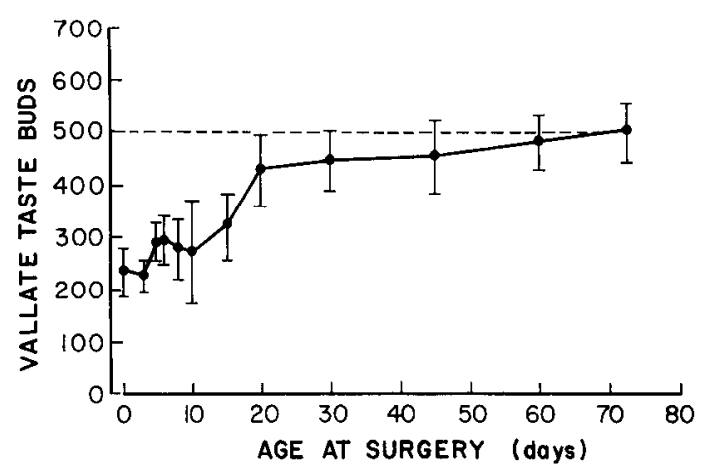

Figure 1. Total number of mature vallate taste buds present (mean \pm 1 $\mathrm{SD}$ ) at at $90 \mathrm{~d}$ is shown as a function of the postpartum age at which the right IXth nerve was removed. Dashed horizontal line indicates that after unilateral denervation in adults at day 75,496 taste buds were present at day 90 .

than $16 \mathrm{~d}$ old or with $125 \mathrm{mg} / \mathrm{kg}$, i.m., of ketamine- $\mathrm{HCl}$, combined with $5 \mathrm{mg} / \mathrm{kg}$, i.p., of sodium pentobarbital for older animals. The older animals also received $50,000 \mathrm{U} / \mathrm{kg}$, i.m., of penicillin 12-24 hr before surgery. Following surgery, a mean of 7.5 animals was killed at each of several ages, extending from 5 to $180 \mathrm{~d}$ postpartum, except for the 34 sets of 3 animals from groups 1,4 , and 8 , which were used to determine the timing of reinnervation by crushed IXth nerves. The vallate papilla was excised and fixed in a solution of $10 \%$ formalin, $10 \%$ sucrose, and $1 \% \mathrm{NH}_{4} \mathrm{OH}$. The tissue was dehydrated through a graded series of ethanol concentrations, transferred to xylene, and embedded in paraffin. Ten-micrometer-thick serial transverse sections of the papilla were stained with iron hematoxylin. Mature vallate taste buds can be identified by the presence of a taste pore. Taste pores were counted in order to minimize the likelihood of counting the same mature taste bud in more than one section (Guth, 1957). We did not systematically examine immature taste buds.

Silver-stained transverse frozen sections cut at $30 \mu \mathrm{m}$ (Winkelmann, 1960) were used to determine the relative latencies of reinnervation of the papilla and its epidermis in 3 groups: AV75/CR75, AV3/CR3, and $\mathrm{CR} 3 / \mathrm{CR} 3$. The circumvallate papilla was taken daily from the sixth to the eighteenth postoperative day from sets of 3 animals from each of these 3 surgical groups. The papilla from each animal was scored for the absence or presence of reinnervation of the papilla, reinnervation of the epidermis lining the papillary trench walls, and mature taste buds. A criterion response was the presence of axons or taste buds in at least 2 of 3 animals.

In addition to visualizing axons within the vallate papilla, we examined cross sections of the trunk of the crushed IXth nerve in three AV75/CR75 animals killed at $90 \mathrm{~d}$. Nerve segments proximal to the site of the crush were embedded in plastic, according to the protocol of Hughes et al. (1983). The $0.5-2.0-\mu$ m-thick plastic sections were stained with paragon (Spurlock et al., 1966) and light micrographs were used to count the total number of myelinated axon profiles present in each nerve. Berthold and Carlstedt (1973) found this method to be $99 \%$ in agreement with counts made from electron micrographs.

Statistical analyses were performed with the MIDAS statistical program at the University of Michigan computer facilities. Analyses included least-squares regression, pairwise ANOVAs, and $t$ tests.

\section{Results}

Following unilateral denervation at day 75 , a mean of 496 vallate taste buds remained at day 90 , as compared to a mean of 610 in normal rats. [Denervated vallate taste buds are known to degenerate in about 1 week (e.g., Guth, 1957; Kennedy, 1972).] Fewer taste buds developed after unilateral denervation at younger ages. Unilateral denervation at day $0,3,5,6,8$, or 10 led to the formation of only 228-295 taste buds by day 90 , representing a significant reduction $(p<0.001$; Fig. 1). Unilateral denervation between days 20 and 75 led to the formation of $430-496$ vallate taste buds by day 90 , significantly more than the number obtained with unilateral denervation between 0 and

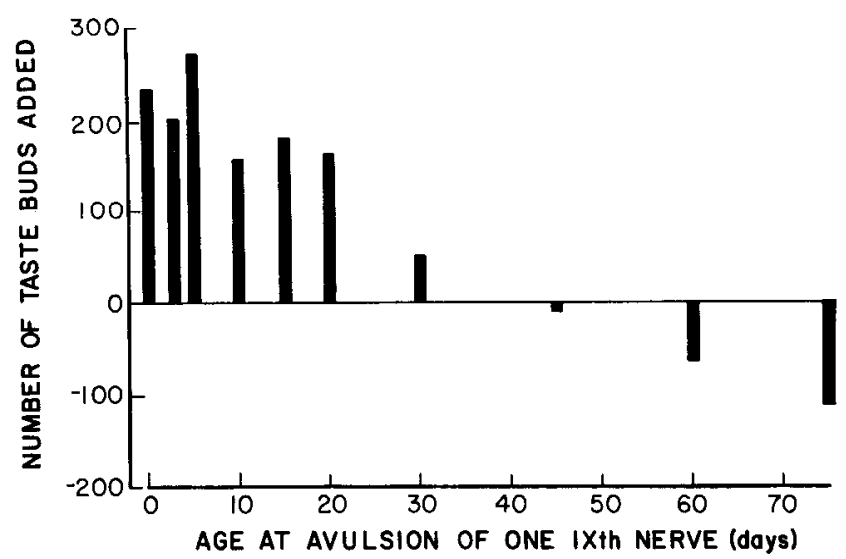

Figure 2. Mean net number of mature taste buds added following unilateral IXth nerve avulsion, shown as a function of the age at avulsion. Hence the ordinate, showing the number of vallate taste buds added, gives the numerical difference between the number of taste buds normally present at the surgical age shown and the number actually present at $90 \mathrm{~d}$.

$10 \mathrm{~d}$ ( $p<0.001$; Fig. 1). At day 90, the AV15/NORM group had an intermediate value of 324 vallate taste buds, significantly more than the number of taste buds at $90 \mathrm{~d}$ for AV0/NORM and AV3/NORM groups $(p<0.01)$ and significantly less than the number of taste buds formed after unilateral denervation at $20-75 \mathrm{~d}(p<0.001)$. In Figure 1 the experimental curve lies below the dashed line that represents the final number of taste buds obtained when one nerve is removed in adults (AV75/ NORM). Thus, there is an early sensitive period that is most pronounced between days 0 and 10 . If there had been no sensitive period for taste bud induction, but merely a continuation of the linear relationship from 20 to $75 \mathrm{~d}$ ( $r=+0.99$; Fig. 1), then nerve removal at day 0 would have produced a mean of 407 taste buds at day 90 and not the observed mean of 234 taste buds.

The taste bud counts shown in Figure 2 represent the net number of mature taste buds added by day 90 beyond the number already present at the time of unilateral avulsion. Hence, the actual number of such added taste buds is the number of taste buds that are ordinarily added minus those that degenerate or fail to form. Theoretically, additional mature taste buds could arise from the de novo formation of taste buds or from the regeneration of immature taste buds that temporarily ceased to develop after unilateral denervation. Because AV3/NORM animals showed no short-term loss of mature taste buds, the primary process for this age group must have been development, rather than re-formation. Intermediate-term avulsion (e.g., AV15/NORM and AV30/NORM) led to an initial period of taste bud loss, indicating degeneration (Fig. 3), but these groups continued to add taste buds up to day 90 (Figs. 2 and 3). The most obvious result of late avulsion, as represented by AV75/ NORM animals, was that some mature taste buds degenerated.

Table 1 lists the mean number of vallate taste buds at 21,45 , and $90 \mathrm{~d}$ as a function of the time of unilateral IXth nerve avulsion. Note that after one IXth nerve was removed, between days 0 and 10 , there was no increase in taste bud numbers beyond day 45 , whereas the later times of nerve removal for AV15/NORM, AV20/NORM, and AV30/NORM animals resulted in the continuing addition of taste buds till day 90 .

Would taste buds form if the nerve were crushed in order to delay reinnervation beyond the $0-10 \mathrm{~d}$ sensitive period? When 


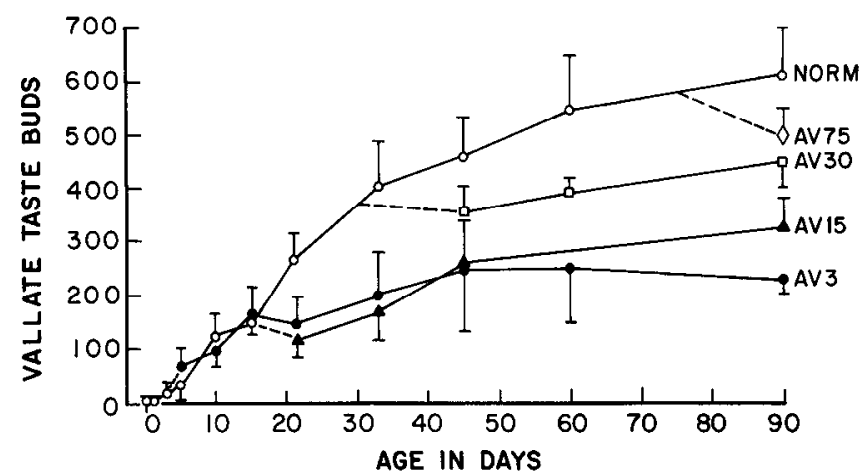

Figure 3. Increase over time in vallate taste bud numbers, shown after unilateral removal of the right IXth nerve on the day indicated at the right of each curve: AV75/NORM ( $\diamond), A V 30 / N O R M(\square)$, AV15/NORM (A), AV3/NORM (@). Taste bud proliferation is also shown for normal animals: NORM/NORM $(O)$. Dashed lines indicate the change in the number of mature taste buds between the time of operation and the initial postoperative measurement. Data points are means $\pm 1 \mathrm{SD} ; n=$ 5-9 animals/data point.

the right IXth nerve was avulsed at day 3 and the left nerve crushed at day 3 , there was a profound and permanent impairment of taste bud proliferation that was not exacerbated by crushing again at day 10 (AV3/CR3 = 30 taste buds and AV3/ CR3 $+10=32$ taste buds at day 90; Fig. $4 A$ ). The 30 taste buds that formed after nerve crush at day 3 represented less than $10 \%$ of those forming after the left IXth nerve was crushed at day 75 or crushed at both days 75 and 82 (AV75/CR75 = 405 and AV75/CR $75+82=372$; Fig. 4C). Even though some axons that were crushed at day 3 regenerate back to the gustatory epidermis by day 13 (Fig. $5, A, B$ ), they only produce a few taste buds (Fig. $4 A$ ). If innervation during the first 10 postnatal days is the important factor in taste bud development, then nerve crush at day 10 should allow many taste buds to be formed. With CR 10, the number of taste buds formed was greatly increased $(\mathrm{AV} 3 / \mathrm{CR} 10=207$ versus $\mathrm{AV} 3 / \mathrm{CR} 3=30$ taste buds) cven after a second crush at day 17 (AV3/CR10 $+17=151$ taste buds; Fig. $4 B$ ). Thus, crushing the IXth nerve at day 3 causes a much greater suppression of taste bud development than crushing the nerve at day 10 . Indeed, a nerve that had been crushed at day 10 was nearly as effective in forming taste buds

Table 1. Number of vallate taste buds present at 21,45 , or $90 \mathrm{~d}$ postpartum in normal animals, or in animals that had one IXth nerve removed at 1 of 9 times from 0 to $30 \mathrm{~d}$ postpartum

\begin{tabular}{llll}
$\begin{array}{l}\text { Age at } \\
\text { operation } \\
\text { (d) }\end{array}$ & \multicolumn{3}{l}{ Age when killed } \\
\cline { 2 - 4 } & 21 & 45 & 90 \\
\hline Normal & $267 \pm 49$ & $460 \pm 74$ & $610 \pm 87$ \\
0 & $141 \pm 50$ & $225 \pm 90$ & $234 \pm 45$ \\
3 & $148 \pm 57$ & $250 \pm 117$ & $228 \pm 29$ \\
5 & $162 \pm 53$ & $298 \pm 62$ & $294 \pm 37$ \\
6 & $105 \pm 54$ & $279 \pm 57$ & $295 \pm 50$ \\
8 & $170 \pm 52$ & $279 \pm 59$ & $280 \pm 58$ \\
10 & $203 \pm 87$ & $330 \pm 26$ & $276 \pm 95$ \\
15 & $117 \pm 28$ & $258 \pm 80$ & $324 \pm 58$ \\
20 & - & $251 \pm 37$ & $430 \pm 63$ \\
30 & - & $356 \pm 48$ & $445 \pm 54$
\end{tabular}

${ }^{a}$ Mean $\pm 1 \mathrm{SD} ; n=6 /$ group.

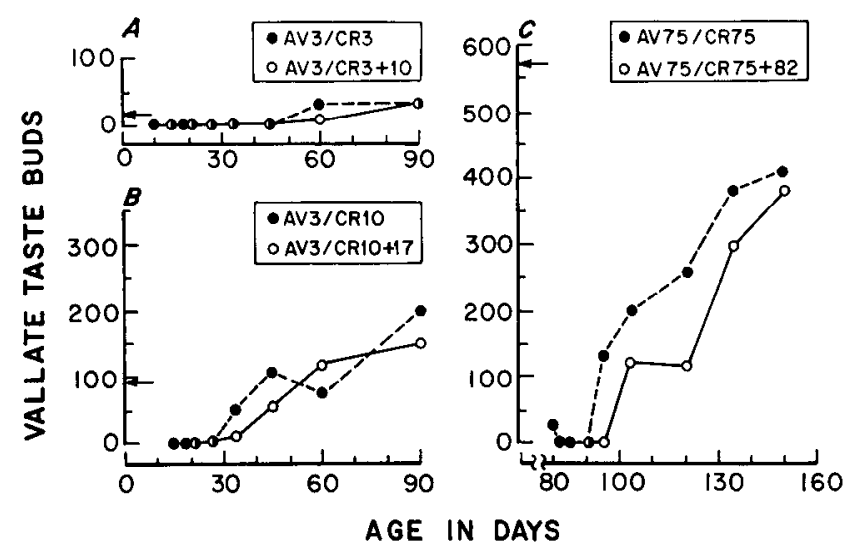

Figure 4. Following combined right IXth nerve avulsion and left IXth nerve crush, the proliferation of vallate taste buds is shown as a function of age. Open circles represent animals in which the left IXth nerve received a second crush $7 \mathrm{~d}$ after the first. $A-C$, Arrow against the ordinate indicates the number of mature taste buds present in normal controls at days 3,10 , and 75 , respectively.

as a completely normal nerve (AV3/CR10 $=207$ versus AV3/ NORM $=228$ taste buds at day 90 ).

We also evaluated the development and maintenance of vallate taste buds when both IXth nerves were crushed at day 3 . One CR 3 nerve produced 30 taste buds at day $90(\mathrm{AV} 3 / \mathrm{CR} 3=$ 30 ), whereas two CR 3 nerves produced almost 5 times as many (CR3/CR3 = 144). After taste bud development had been completed in the CR3/CR3 group, one of the two CR3 nerves could maintain 99 taste buds at day 90 (CR3 + AV75/CR3 =99).

Figure 5 indicates the time of reinnervation of the dermal core and trench wall epidermis of the papilla, as well as the time of initial reappearance of taste buds for each of 3 groups: CR3/

\section{A) CR3/CR3

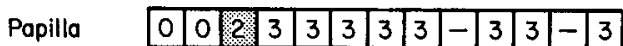

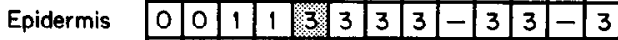 \\ \begin{tabular}{ll|lllllllllll|l|l|l|l|l|} 
Taste Buds & 0 & 0 & 0 & 0 & 0 & 0 & 0 & 1 & - & 2 & - & 3 \\
\hline
\end{tabular} \\ B) $A V 3 / C R 3$ \\ Papilla $\quad$\begin{tabular}{l|l|l|l|l|l|l|l|l|l|l|l|l|}
0 & 0 & 0 & 2 & 3 & 3 & 3 & 3 & 3 & 3 & 3 & 3 & 3 \\
\hline
\end{tabular}

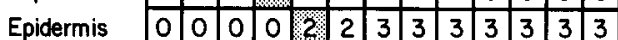 \\ Taste Buds $\begin{array}{llllllllllllllllll} & 0 & 0 & 0 & 0 & 0 & 0 & 0 & 0 & 0 & 0 & 0 & 1 & 1\end{array} \ldots$ \\ C) AV75/CRT5

\begin{tabular}{|c|c|c|c|c|c|c|c|c|c|c|c|c|c|}
\hline Papllla & - & & - & 0 & 0 & 2 & 3 & 3 & & 3 & & & \\
\hline $\mathrm{mis}$ & - & - & - & 0 & 0 & 0 & 0 & 3 & 3 & 3 & 3 & 3 & 3 \\
\hline Taste Buds & - & - & - & 0 & 0 & 0 & 0 & 0 & 0 & 1 & & 3 & 3 \\
\hline
\end{tabular}

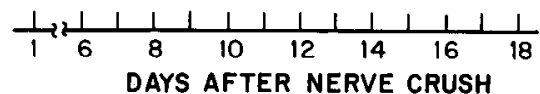

Figure 5. Timing of reinnervation and taste bud re-formation after nerve crush, shown for 3 groups of animals: $A, \mathrm{CR} 3 / \mathrm{CR} 3 ; B, \mathrm{AV} 3 / \mathrm{CR} 3$; and $C, \mathrm{AV} 75 / \mathrm{CR} 75$. Papilla, initial reinnervation of the dermal core of the papilla's centrum; epidermis, initial reinnervation of the trench wall epithelium; taste buds, initial reappearance of mature taste buds. Squares indicate, at each postoperative age, how many of 3 animals $(0$, 1,2 , or 3 of 3 ) exhibited the indicated trait; a dash (-) indicates that no data were obtained at that age. The recovery sequence for all surgical protocols was as follows: Papilla reinnervated first, epithelium reinnervated second, and taste bud reappearance third, as shown by the location of the shaded squares representing the initial occurrence of a criterion response ( 2 or 3 of 3 animals). $B$, The criterion level for taste buds had not been achieved by $18 \mathrm{~d}$ after nerve crush (shaded square at right margin). 
CR3, AV3/CR3, and AV75/CR75. A positive outcome in at least 2 of the 3 animals evaluated on each day was established as the criterion response (shaded squares in Fig. 5). The regenerating IXth nerve axons reinnervated the papilla first and invaded the trench wall epidermis later. The rate of nerve regrowth to the papilla for the younger animals was $1.8 \pm 0.3 \mathrm{~mm} / \mathrm{d}$ in $\mathrm{CR} 3 / \mathrm{CR} 3$ (mean $\pm 1 \mathrm{SD}$ ) and $1.6 \pm 0.3 \mathrm{~mm} / \mathrm{d}$ in AV3/CR3; for the older animals, AV75/CR 75, the rate was $1.8 \pm 0.3$ $\mathrm{mm} / \mathrm{d}$. That reinnervation of the papilla occurred $3-4 \mathrm{~d}$ sooner in younger animals can be accounted for by the shorter distance the nerves had to traverse in the younger (mean $=14 \pm 4 \mathrm{~mm}$; $n=6)$ than in the older $(20 \pm 3 \mathrm{~mm} ; n=7)$ animals. For all groups, axons invaded the trench wall epidermis $1-2 \mathrm{~d}$ after rcinncrvation of the papilla. However, re-formation of taste buds followed the reinnervation of trench wall epidermis by 3 d for AV75/CR75 animals, by $5 \mathrm{~d}$ for CR3/CR3 animals, and not before $10 \mathrm{~d}$ for AV3/CR3 animals. It is unlikely that these latencies of taste bud reappearance were strongly linked to the number of taste fibers, since CR3/CR3 animals had a total of $1670 \pm 430$ myelinated axons, whereas AV75/CR75 animals had a shorter latency, but $1587 \pm 495$ myelinated axons.

In normal animals, there are nearly equal numbers of taste buds in the 4 trench walls (about 150 each in the left and right inner and outer walls). $T$ tests for paired observations indicate no significant difference in number of taste buds on the right versus the left side of the normal vallate papilla $(p>0.05)$. However, with right nerve avulsions performed at day 15 or later, there were consistently 11-14\% fewer taste buds in the right versus the left outer trench wall $(p<0.02)$, implying that there is a small ipsilateral bias in vallate taste bud innervation. Significant differences were also found for inner versus outer wall distributions of AV0/NORM, AV5/NORM, AV6/NORM, AV30/NORM, AV45/NORM, AV3/CR10, and AV75/CR75 groups $(p<0.01)$, indicating a more effective nerve supply to the inner trench walls in these unilaterally innervated papillae.

\section{Discussion}

Vallate taste buds will form during development only if the papilla is innervated (Hosley et al., 1987). On the basis of the present results, we propose that this neural induction of taste buds occurs during an early sensitive period. Several lines of evidence argue that innervation is especially important during the first $10 \mathrm{~d}$ after birth. The strongest evidence is that unilateral denervation causes the most severe taste bud deficits when the IXth nerve is removed between days 0 and 10 (Fig. 1). Later avulsion of the IXth nerve has lesser effects. These findings are supported by the following facts: (1) taste bud deficits are as profound when the one remaining IXth nerve is crushed at day 3 as when it is crushed at day 3 and again at day 10 (AV3/ $\mathrm{CR} 3=30 ; \mathrm{AV} 3 / \mathrm{CR} 3+10=32$ taste buds at day 90 ), and (2) the inductive capacity of a IXth nerve crushed at day 10 is similar to that of an intact normal IXth nerve $(\mathrm{AV} 3 / \mathrm{CR} 10=$ 207; AV3/NORM $=228$ taste buds at day 90).

A priori, the number of taste buds present at day 90 may be expected to be a function of the number and timing of arrival of taste axons during development, and of the number of taste axons maintaining taste buds at day 90 . The concept of a sensitive period presumes that the timing of innervation is important for development. Unilateral denervation at various ages (AV0-AV75) provides a suitable test of timing because, in each group with unilateral avulsion, taste buds were maintained at day 90 only by the normal left IXth nerve, while in development the normal right IXth nerve was also present for controlled times. The results of this parametric study indicate that the number of mature taste buds that arise is decreased most profoundly when the right IXth nerve is absent during a sensitive period that is maximal from 0 to $10 \mathrm{~d}$ postpartum. This further implies that only a few taste buds should be produced if a nerve is crushed in time to eliminate all axons from the papilla during much of the $0-10 \mathrm{~d}$ sensitive period. In fact, after avulsion of one IXth nerve and crush of the other at day 3 , axons began to invade the gustatory epithelium around postnatal day 13 . In these AV3/CR3 animals, only 30 taste buds developed, mainly between days 45 and 90 , whereas 207 taste buds developed in AV3/CR10 animals when the nerve crush was delayed until after the sensitive period. Crushing the IXth nerve may have killed some of the taste neurons, but the trauma to these neurons should have been similar whether the nerve crush was carried out at day 3 or day 10 . Earlier, we proposed that taste axons interact with progenitor cells during development to form stem cells, whose daughters comprise the cells of the taste bud (Hosley et al., 1987). In the absence of innervation during the sensitive period, taste progenitor cells may degenerate or adopt alternative roles. Both unpublished observations and the present experiments with crushed nerves suggest that a neonatally denervated gustatory epithelium changes and becomes irreversibly unresponsive to delayed gustatory innervation.

Although a $0-10 \mathrm{~d}$ sensitive period may prevail in the development of the vallate taste bud population, it is inappropriate to generalize either to the late-maturing subset of taste buds or to any individual taste bud. Since $0-10 \mathrm{~d}$ represents the postnatal period when few mature taste buds are present, and the greatest number of taste buds are developing, the quantitative effects of denervation at this time are accordingly profound. Late-maturing taste buds might have later sensitive periods, and, if there are relatively few of them, late denervation would cause only a small reduction in the taste bud population. Taste buds with late sensitive pcriods may account for the more modest taste bud deficits observed after unilateral avulsion between days 20 and 60 . Since there is a constant taste bud density from 40 to $90 \mathrm{~d}$ (Hosley and Oakley, 1987), these late-appearing taste buds may form only as the growth of the epithelium allows. The duration of the sensitive period for an individual progenitor cell/taste bud cannot be determined from our data. It may be much shorter than $10 \mathrm{~d}$.

Regenerating axons develop or re-form taste buds after a lengthy latent period; most are formed more than a month after nerve crush in AV3/CR3, AV3/CR10, AV3/CR10 + 17, AV75/ CR75, and AV75/CR75 + 82 groups. A similar prolonged addition of taste buds is also found in AV15/NORM, AV20/ NORM, and AV30/NORM animals that have one normal nerve. By contrast, AV0/NORM, AV3/NORM, AV5/NORM, AV6/ NORM, AV8/NORM, and AV10/NORM groups all reach maximal numbers of taste buds by day 45 . It is unclear why the AV0-10/NORM groups did not form taste buds after day 45 .

Unilateral avulsion of the IXth nerve in adult rats causes a 5-19\% loss of vallate taste buds (Whiteside, 1927; Guth, 1963; Oakley, 1974; Hosley et al., 1987). However, unilateral avulsion in newborns or 3-d-old rats causes a $63 \%$ taste bud deficit. Thus, in development, one nerve induces about 230 taste buds (AV0/ NORM, AV3/NORM), whereas one adult nerve trophically maintains 496 taste buds (AV75/NORM). Why can't the IXth 
nerve induce as many taste buds as it can maintain (Hosley et al., 1987) or re-form in adults (State, 1977)? Experiments with nerves crushed at day 3 support the concept that a taste nerve can maintain more taste buds than it can induce in development. A CR 3 nerve induces 30 taste buds (AV3/CR3 = 30) but can maintain 133 (CR3/AV75 = 133). Similarly, a normal nerve that was paired with a crushed nerve during development can maintain more taste buds (CR3 + AV75/NORM = 351) than it can form alone (AV3/NORM = 228) (Hosley et al., 1987). Thus, experiments with unilateral avulsion or with crushed nerves lead to the same conclusion: It is easier to re-form or maintain taste buds than to develop them, perhaps because of a more potent neural influence or an improved cellular response in older animals. More generally, taste bud regeneration does not recapitulate taste bud development.

The time course of reinnervation and taste bud regeneration observed in adult rats is similar to that described for adult gerbils whose chorda tympani nerve was crushed and assayed at daily intervals by the Winkelmann silver stain (Cheal and Oakley, 1977) and electrophysiological recording (Cheal et al., 1977). After the gerbil's chorda tympani nerve was crushed, the axons regenerated at a mean rate of $2.2 \mathrm{~mm} / \mathrm{d}$, invaded the gustatory epithelium in $8-10 \mathrm{~d}$, and formed functional taste buds $1-2 \mathrm{~d}$ later. In the present experiment with adult rats (AV75/CR75), regenerating axons grew at a rate of $1.8 \mathrm{~mm} / \mathrm{d}$, re-entered the vallate papilla's epidermis within about $13 \mathrm{~d}$ after surgery, and re-formed taste buds 2-3 d later. By contrast, taste buds did not form in the gustatory epithelium of neonates until either $5 \mathrm{~d}$ (CR3/CR3) or more than $8 \mathrm{~d}(\mathrm{AV} 3 / \mathrm{CR} 3)$ after reinnervation of the epidermis. It is reasonable to assume that in neonates, as in adults, the first taste buds observed were those re-formed from stem cells at previously innervated sites, rather than those induced de novo. The latency of taste bud appearance should depend on which papilla had more targets, the number of axons entering the papilla, and whether the pathways of regenerating axons in young rats might have been disrupted by the continued growth of the papilla.

The data indicate that when innervation density falls, there is a reduction in the percentage of bilaterally innervated taste buds. In $75 \mathrm{~d}$ normal animals, $37.5 \%$ of the 610 taste buds are unilaterally maintained: $\mathrm{AV75/NORM}=495.6 ;(610-495.6) \times$ $2=228.8$ unilaterally innervated $=37.5 \%$ of 610 , leaving $62.5 \%$ (381) of the taste buds bilaterally innervated. Unilateral or bilateral nerve crush at day 3 reverses these percentages. In CR3/ CR3, $62.5 \%$ of the 144 taste buds are unilaterally innervated: $\mathrm{CR} 3+\mathrm{AV} 75 / \mathrm{CR} 3=99 ;(144-99) \times 2=90=62.5 \%$ of 144 , and hence $37.5 \%(54)$ are bilaterally innervated. The reversal of the normal ratio of unilaterally to bilaterally innervated taste buds is significant ( $p<0.001$; chi-square test). CR3/CR3 animals have virtually the same percentage of bilaterally innervated taste buds as do CR3/NORM animals, where $61 \%$ of the 340 vallate taste buds are unilaterally innervated and 39\% are bilaterally innervated. Thus, the percentage of bilaterally innervated taste buds is the same whether 1 or 2 nerves were crushed at day 3. If bilateral overlap is a stochastic process, axons of the left and right IXth nerves should disperse randomly in the epithelium and produce bilaterally innervated taste buds in proportion to the number of sites of nerve overlap. Assuming mass action, the number of sites of bilateral overlap should increase as the product of the axon numbers in the 2 nerves. Given the above numbers of bilaterally innervated taste buds and the counts of myelinated axons in the IXth nerve (Hosley et al., 1987), it is possible to test this prediction. On the basis of myelinated axon counts of 835 axons in CR3 nerves and 1897 axons in normal nerves, a stochastic process predicts that the number of bilaterally innervated taste buds will drop from 381 in NORM/ NORM to 167 in CR3/NORM to 74 in CR3/CR3. I he observed decreases were from 381 to $133 \pm 31$ (Hosley et al., 1987) to $54 \pm 26$. Hence, to a first approximation, the number of bilaterally innervated vallate taste buds is a function of the random overlap of axons from the right and left IXth nerves. Such calculations assume that the number of taste axons is proportional to the total number of myelinated axons.

The presence of the crushed nerve in CR3/NORM animals leads to 112 more taste buds (CR3/NORM - AV3/NORM = $340-228=112$ ). Similarly, the crushed left nerve in CR3/ CR3 animals contributes 114 taste buds (CR3/CR3 - CR3/ AV3 $=144-30=114$ ). Thus, CR3 as a second nerve in CR3/ NORM and CR3/CR3 added the same number of taste buds (112-114) and led to the same percentage (38\%) of bilaterally innervated taste buds. However, only about one-half of the 114 taste buds added by the second CR 3 nerve were bilaterally innervated in $C R 3 / C R 3$, whereas all were bilaterally innervated in CR3/NORM, as predicted from the continuous presence of the normal left IXth nerve, with its larger number of axons, which greatly increases the probability of nerve overlap.

Results obtained from the study of AV3/NORM animals reveal that a nonlinear relationship exists between the number of axons and the number of taste buds formed. Animals in this group, with one nerve, have $50 \%$ of the normal number of myelinated axons, yet form only $37 \%$ of the normal number of vallate taste buds. Similarly, AV3/CR3 animals have $22 \%$ of the normal number of axons at day 90 , but have only $7 \%$ of the normal number of taste buds. It is possible that when axons are spread thinly in the vallate papilla, their density can fall below the threshold for taste bud induction. Synergistic interactions among taste axons have been described previously (Hosley et al., 1987), and the present results provide additional examples of such interactions between the right and left IXth nerves in the formation of taste buds. Animals in the CR3/CR3 group had a mean of 84 more taste buds than were predicted by linear summation. [Since AV3/CR3 $=30$, the nonlinear, or synergistic, increment for CR3/CR3 is $144-(30 \times 2)=84$.] At least 54 of these taste buds can be accounted for by bilateral innervation. Similarly, $($ AV3 $/$ CR3 $=30)+($ AV3 $/$ NORM $=228)=258$ a linear sum that is 82 taste buds short of the 340 observed when a CR3 and a normal nerve interact (CR3/NORM = 340). Such synergistic interactions between the right and left IXth nerve suggest that more than one axon is required to form a taste bud.

\section{Conclusions}

1. Many vallate taste buds are induced by the IXth nerve during an early sensitive period from 0 to $10 \mathrm{~d}$ postpartum.

2. Taste bud regeneration does not recapitulate taste bud development. Specifically, the IXth nerve will re-form or maintain more taste buds in the adult than it will induce during development.

3. Taste axons of the right and left IXth nerve interact synergistically; thus, more than one axon may be required to form a taste bud.

4. The following results support the view that taste bud for- 
mation is a probabilistic function of the number of axons and potential target sites:

a. Taste buds are slow to reappear after nerve crush at day 3 postpartum.

b. The number of taste buds formed is a nonlinear function of the number of axons present.

c. The percentage of taste buds that are bilaterally innervated is related to the likelihood of overlap of axons of the right and left IXth nerves.

\section{References}

Berthold, C. H., and T. Carlstedt (1973) Fixation and numerical estimation of myelinated nerve fibers during initial myelination in the cat. Neurobiology 3: 1-18.

Cheal, M. L., and B. Oakley (1977) Regeneration of fungiform taste buds: Temporal and spatial characteristics. J. Comp. Neurol. 172: 609-626.

Cheal, M. L., W. P. Dickey, L. B. Jones, and B. Oakley (1977) Taste fiber responses during reinnervation of fungiform papillae. J. Comp. Neurol. 172: 627-646.

Farbman, A. I. (1965) Electron microscope study of the developing taste bud in rat fungiform papilla. Dev. Biol. $11: 110-135$.

Guth, L. (1957) The effects of glossopharyngeal nerve transection on the circumvallate papilla of the rat. Anat. Rec. 128:715-731.

Guth, L. (1963) Histological changes following partial denervation of the circumvallate papilla of the rat. Exp. Neurol. 8: 336-349.

Hermann, F. (1884) Beitrag zur Entwicklungsgeschiste des Geschmacksorgans beim Kaninchen. Arch. mikr. Anat. 24: 216-229.
Hosley, M. A., and B. Oakley (1987) Development of the vallate papilla and taste buds in rats. Anat. Rec. (in press).

Hosley, M. A., S. E. Hughes, and B. Oakley (1987) Neural induction of taste buds. J. Comp. Neurol. (in press).

Hughes, S. E., H. E. Sloan, L. B. Jones, and B. Oakley (1983) Colchicine reduces myelin thickness and axoplasm volume. Neurosci. Lett. 37: 181-186.

Kennedy, J. G. (1972) The effects of transection of the glossopharyngeal nerve on the taste buds of the circumvallate papilla of the rat. Arch. Oral Biol. 17: 1197-1207.

Oakley, B. (1970) Reformation of taste buds by crossed sensory nerves in the rat's tongue. Acta Physiol. (Scand.) 79: 88-94.

Oakley, B. (1974) On the specification of taste neurons in the rat tongue. Brain Res. 75: 85-96.

Spurlock, B. O., M. S. Skinner, and A. A. Kattine (1966) A simple rapid method for staining epoxy-embedded specimens for light microscopy with the polychromatic stain Paragon-1301. Am. J. Clin. Pathol. 46: 252-258.

State, F. A. (1977) Histological changes following unilateral reinnervation of the circumvallate papilla of rat. Acta Anat. 98: 343-352.

Torrey, T. W. (1940) The influence of nerve fibers upon taste buds during embryonic development. Proc. Natl. Acad. Sci. USA 26: 627634.

von Vintschgau, M., and J. Hönigschmied (1876) Nervus glossopharyngeus und schmeckbecher. Arch. Ges. Physiol. 14: 443-448.

Whiteside, B. (1927) Nerve overlap in the gustatory apparatus of the rat. J. Comp. Neurol. 44: 363-377.

Winkelmann, R. K. (1960) Nerve Endings in Normal and Pathologic Skin, pp. 159-161, C. C. Thomas, Springfield, MA. 